\title{
Evaluation of Commercial Disinfectants against Staphylococcus lentus and Micrococcus spp. of Poultry Origin
}

\author{
Otun Saha, ${ }^{1}$ Nadira Naznin Rakhi, ${ }^{2}$ Arif Istiaq, ${ }^{3}$ Israt Islam, ${ }^{1}$ Munawar Sultana, \\ M. Anwar Hossain, ${ }^{1,4}$ and Md. Mizanur Rahaman ${ }^{1}{ }^{1}$ \\ ${ }^{1}$ Department of Microbiology, University of Dhaka, Dhaka-1000, Bangladesh \\ ${ }^{2}$ Department of Biotechnology and Genetic Engineering, \\ Bangabandhu Sheikh Mujibur Rahman Science and Technology University, Gopalganj, Bangladesh \\ ${ }^{3}$ Department of Developmental Neurobiology, Graduate School of Medical Sciences, Kumamoto University, Kumamoto, Japan \\ ${ }^{4}$ Jashore Science and Technology University, Jashore, Bangladesh \\ Correspondence should be addressed to Md. Mizanur Rahaman; razu002@du.ac.bd
}

Received 14 April 2020; Revised 26 August 2020; Accepted 27 August 2020; Published 25 September 2020

Academic Editor: Antonio Ortega-Pacheco

Copyright (C) 2020 Otun Saha et al. This is an open access article distributed under the Creative Commons Attribution License, which permits unrestricted use, distribution, and reproduction in any medium, provided the original work is properly cited.

\begin{abstract}
Introduction. Effective sanitation strategies for poultry farms require an appropriate selection of the disinfectant based on the contaminants present and their sensitivity to the disinfectants. Aim. The current study investigated the prevalence of streptococci/ micrococci in poultry farms of Bangladesh and the efficacy of commercial disinfectants (Savlon, Lysol, Quatovet, Virkon S, and Virocid) along with alcohol against these pathogens to adopt appropriate strategies. Materials and Methods. Conventional approaches and the $16 \mathrm{~S}$ rRNA gene sequencing were performed to confirm the isolates at the species level along with microtiter biofilm assay to determine their biofilm-forming ability. Efficacy of the disinfectants was tested against those isolates using agar well diffusion and minimum inhibitory concentration (MIC) test by broth dilution method using different dilutions of the disinfectants. Results. Staphylococcus lentus $(n=32)$, Micrococcus luteus $(n=7)$, and Micrococcus aloeverae $(n=4)$ were confirmed among 102 presumptively screened streptococci/micrococci isolates from 43 samples. No single disinfectant showed equally high efficacy against all three bacterial species in agar well diffusion test, although Virocid showed the lowest MIC against all three of them. Lysol was least effective among the commercial disinfectants by both MIC and diffusion method, although each commercial disinfectant was more effective than alcohol. Considering both the average diameter of the inhibition zones and the MIC values, efficacy can be interpreted as Virocid > Quatovet $>$ Savlon > Virkon S > Lysol. Although the efficacy decreased with decreasing concentration, the disinfectants retained a satisfactory level of efficacy at $50 \%$ concentration. Among test pathogens, $M$. aloeverae was the most sensitive to the disinfectants and the weakest biofilm producers, whereas 4/14 S. lentus and 1/5 M. luteus were strong biofilm producers, which may cause more reduction in the efficacy in environmental conditions. Conclusion. As no ideal disinfectant was found in the study, the efficacy of the disinfectants should be routinely evaluated and validated to ensure the sanitation standards in the poultry sector.
\end{abstract}

\section{Introduction}

Poultry farming is one of the most promising and fastest growing agrobased enterprises in Bangladesh contributing about one-third of total GDP (18.6\%) from the agricultural sector of the country $[1,2]$. Currently, it is even growing at a rate of $20 \%$ per annum [2]. Besides, poultry is one of the largest domestic animal stocks globally including Bangladesh $[2,3]$. So, ensuring biosecurity for poultry is mandatory for economic prosperity and public health. But unfortunately, the manpower comprised of more than 3 million people associated directly with this sector [4] is mostly unskilled [5] and lacking proper knowledge of personal hygiene and sanitation strategies, thus risking this promising sector. Moreover, the lack of sufficient knowledge and training on the sanitation program is making the zoonotic disease transmission difficult to control/prevent leading to high health risks for both animals and farmers [6]. 
The recent reports showed that most of the poultry farms do not practice the benchmark guidelines of biosecurity [7]. Spraying disinfectants in sheds and removing feces were the only sanitation schemes adopted in the farms $[8,9]$. Even those disinfectants are used without regular validation and evaluation of efficacy, while the efficacy of the disinfectants is influenced by formulation, level of organic load, humidity, temperature, dilution rate, $\mathrm{pH}$ and hardness of water, and other factors $[9,10]$. Also, using disinfectants without validation and evaluation may cause the high selective pressure leading to the gradual decrease in sensitivity of the organisms to the disinfectants used and even cross-resistance to antibiotics of public health concerns [11]. Thus improper sanitation procedures might be ineffective in disease control lowering bird performance [11]. So, the evaluation of the disinfectants' efficacy should be in priority to select the suitable disinfectant by minimizing the microbial load before slaughtering and processing of the carcasses.

Gram-positive organisms including Micrococcus spp., Corynebacterium spp., and Staphylococcus spp. are predominant in poultry microflora [12] and prevalently found in barns [13], in entry area [14], and even in bioaerosol derived from animal dander and feces of the poultry houses [15]. Micrococcus spp., Enterococcus spp., and Staphylococcus spp. are also found predominating on eggshells $[15,16]$, while eggshells are used in the poultry feeds as the source of calcium [17]. So, this practice along with lack of personal hygiene practices among the farm workers observed in the previous studies [8], which included no practice of disinfecting hands and feet before entering and exiting and even eating and touching eyes, faces, bodies, and clothing without washing hands, etc., denotes the potential of health hazards in both poultry and poultry farm workers. Besides, Staphylococcus aureus, S. xylosus, S. lentus, S. auricularis, S. hominis, Bacillus cereus, and Micrococcus spp. [15] are considered as the main issues of meat safety due to faulty implementation of Hazard Analysis Critical Control point (HACCP) rather than the poultry pathogens [18]. However, although Staphylococcus spp. are not considered as one of the prime poultry pathogens, they are associated with different infections in birds, especially the coagulase positive Staphylococcus spp. and S. aureus as well as coagulasenegative staphylococci [19]. Among coagulase-negative staphylococci, S. xylosus, S. lentus, and S. cohnii are predominating and associated with central nervous system of poultry [20]. On the other hand, Micrococcus spp. are generally considered as nonpathogen, and Micrococcus pyogenes var. albus and $M$. candidus were isolated from birds with aerosaccitis disease [21] and also reported to cause secondary infections $[15,21]$. Moreover, Micrococcus is one of the dominant species found in the particulate matters of poultry houses that can cause different diseases in humans and animals [15].

However, these reports are from the poultry farms worldwide, while the prevalence of micrococci/staphylococci is not well reported from Bangladesh. Besides, although few studies evaluated efficacy of the disinfectants against poultry pathogens, unfortunately, the efficiency of any disinfectant has never been tested against these group of organisms. So, the current study targets the prevalence of these organisms and the in vitro efficacy of commercial disinfectants against these organisms to devise a sanitation program appropriate for the poultry farms of the country.

\section{Materials and Methods}

2.1. Ethics Approval. Consents were obtained from the owners of the farms before the samples were collected for the study. Besides, the Ethics Committee of the Faculty of Biological Sciences, University of Dhaka, Bangladesh, approved the procedure, Reference 71/Biol.Scs./2018-2019.

2.2. Sample Collection. A total of 43 poultry samples (Cloacal swab, $n=19$; Liver, $n=24$ ) were collected from 3 different poultry farms, with or without disease signs from Manikganj and Narsingdi districts under Dhaka Division, Bangladesh, during the period between 2017 and 2018. After sampling, samples were transferred to the Department of Microbiology, University of Dhaka, within the shortest possible time.

2.3. Screening of Micrococcus and Staphylococcus. Samples were inoculated into nutrient broth (Oxoid, USA) followed by pre-enrichment in brain heart infusion (BHI) broth (Oxoid, USA) according to Food and Drug Administration Bacteriological Analytical Manual (FDA-BAM) [22]. Samples were then directly inoculated onto blood agar (Oxoid, USA) with 5\% sheep blood and mannitol salt agar (MSA) (Oxoid, USA) for screening of Micrococcus spp. and Staphylococcus spp., respectively, along with the biochemical tests (triple sugar iron, indole, methyl-red, VogesProskauer, citrate, catalase, oxidase, and sugar (glucose) fermentation test) following Bergey's manual of determinative bacteriology [23].

2.4. Molecular Identification of the Isolates and Phylogenetic Analyses. Presumptive Micrococcus and Staphylococcus isolates were genotyped by Random Amplified Polymorphic DNA (RAPD) method using arbitrary primer 1283 (5' GCGATCCCCA-3') [24]. 16S rRNA genes of the representative isolates from each RAPD group were amplified by PCR using universal primers 27F (5'-AGAGTTTGATCCTGGCTCAG- $\left.3^{\prime}\right)$ and 1492R (5'-CTACGGCTACCTTGTTACGA- $3^{\prime}$ ) and subjected to sequencing [4]. DNA sequencing was carried out using Applied Biosystems highest capacity-based genetic analyzer (ABI PRISM ${ }^{\circledR} 377$ DNA Sequencer) platforms with the BigDye ${ }^{\circledR}$ Terminator v3.1 cycle sequencing kit chemistry. Raw data were analyzed and assembled followed by submission to NCBI GenBank (MN701067, MN701075, and MN701081). For inferring the evolutionary history of the $16 \mathrm{~S}$ rRNA gene of the selected isolates, neighbor-joining method [24] was used using MEGA7 [25] based on Kimura-2-parameter model.

2.5. Biofilm Assay of Representative Micrococcus and Staphylococcus Isolates. Randomly selected isolates of both Micrococcus and Staphylococcus were subjected to microtiter biofilm 
assay [26]. The assay was performed in duplicate in the 96-well tissue culture plates. The observed optical density (OD) was evaluated to determine the biofilm-forming ability of the isolates on a 4-grade scale (nonadherent, weakly adherent, moderately adherent, and strongly adherent) [26, 27]. This 4-grade was determined by comparing OD with ODc (three standard deviation values above the mean OD of the negative control).

2.6. Selection of Disinfectants. The commercial disinfectants selected for this study were Lysol (active ingredients: benzalkonium chloride, manufactured by Reckitt Benckiser, Bangladesh), Savlon (active ingredients: cetrimide and chlorhexidine gluconate combination, manufactured by ACI, Bangladesh), Virocid ${ }^{\circledR}$ (active ingredients: combination of quaternary ammonium compounds, glutaraldehyde, and alcohol: isopropanol, pineoil; manufactured by CID LINES, Belgium), Quatovet (quaternary ammonium compound, manufactured by THESEO Deutschland $\mathrm{GmbH}$, Germany), and Virkon S (potassium peroxymonosulfate and sodium chloride) along with locally available alcohol (70\% v/v) for laboratory use.

\subsection{Efficacy Testing of Disinfectant and Correlation of Efficacy} with Disinfectant Concentration. The in vitro efficacy testing of the disinfectants against Micrococcus and Staphylococcus was determined by agar well diffusion [28]. Mueller-Hinton agar $\left(\mathrm{Oxoid}^{\mathrm{TM}}, \mathrm{UK}\right)$ plates were inoculated with the pure cultures of the selected isolates using sterile cotton swab and five $7 \mathrm{~mm}$ wells were made, one in the center and the other four about $20 \mathrm{~mm}$ away from the center. $50 \mu \mathrm{L}$ of each disinfectant was added to the wells followed by overnight incubation to determine the zone of inhibition. To investigate the correlation between the disinfectant efficacy and the concentration, varying concentrations $(30 \%, 40 \%, 50 \%$, $60 \%, 70 \%, 80 \%, 90 \%$, and $100 \%$ ) of the disinfectant solutions were prepared and tested for efficacy accordingly. The assay with each concentration was performed in triplicate to determine the selected MIC values of the isolates [28]. MICs of disinfectants in these isolates were determined using broth microdilution as described by Olasehinde et al., 2015 [29].

2.8. Statistical Analysis. Descriptive statistics including mean, standard deviation (SD), and the range were used to summarize the antimicrobial properties of all disinfectants using Social Sciences (SPSS) version 21.0 software (IBM, Armonk, NY, USA) [30] and Microsoft Excel.

\section{Results}

3.1. Isolation of Staphylococcus and Micrococcus Isolates. Following the inoculation of 43 poultry samples onto mannitol salt agar and blood agar, a total of 80 presumptive Staphylococcus isolates and 22 presumptive Micrococcus isolates were retrieved, respectively. So, a total of 102 isolates were investigated phenotypically and genotypically to isolate Staphylococcus and Micrococcus. According to the biochemical test results, 11 out of 22 retrieved isolates from blood agar and 32 out of 80 isolates from mannitol salt agar were presumptively Micrococcus and Staphylococcus, respectively. Later, RAPD analysis of the isolates differentiated these 43 isolates into 3 different groups (Figure S1). Sequencing of $16 \mathrm{~S}$ rRNA gene of the representative isolates of each group identified RAPD groups 1,2 , and 3 as S. lentus $(n=32), M$. luteus $(n=7)$, and $M$. aloeverae $(n=4)$, respectively (Figure 1). So, out of a total of 102 isolates, $S$. lentus was more prevalent $(31.37 \%, 32 / 102)$ than Micrococcus spp. $(10.78 \%, 11 / 102)$. The prevalence of both $M i$ crococcus spp. and Staphylococcus spp. was higher in cloacal swab samples (72.72\%, 8/11 and 59.38\%, 19/32, respectively) than in liver samples $(27.27 \%, 3 / 11$ and $40.63 \%, 13 / 32$, respectively).

3.2. Biofilm Assay of the Representative Isolates. Twenty-two isolates (14 S. lentus, $5 \mathrm{M}$. luteus, and 3 $M$. aloeverae) were randomly selected and subjected to biofilm assay. Thirteen out of those 22 isolates (59.09\%) were found to be biofilm producers. Among the isolates, $28.57 \%$ (4/14) of S. lentus and 20\% (1/5) of M. luteus possessed strong biofilm-forming ability, while $21.43 \%$ (3/14) of S. lentus were found to be moderate biofilm producers (Figure 2 and Table S1). In this study, M. aloeverae showed relatively weak biofilm-forming ability compared to others.

3.3. In Vitro Efficacy Testing of the Disinfectants. Agar well diffusion test of 22 selected isolates (Micrococcus spp., $n=8$ and $S$. lentus, $n=14$ ) against the disinfectants showed that, except for Virkon S and Savlon, $M$. aloeverae was most sensitive to disinfectants, while $M$. luteus was the least sensitive to all but Virkon S among the three species tested. Besides, Lysol gave the lowest zones of inhibition against all the isolates except $M$. aloeverae (Table 1)). However, all of the commercially available disinfectants were more effective than alcohol (70\% v/v) (Figure 3). Savlon showed the highest zone of inhibition (D) $(37.13 \pm 0.7 \mathrm{~mm})$ for S. lentus followed by Virocid $(35.25 \pm 0.42 \mathrm{~mm})$, Quatovet $(33.9 \pm 0.67 \mathrm{~mm})$, and Virkon $S(32.42 \pm 0.4 \mathrm{~mm})$, respectively. In case of M. luteus, Virkon S was most effective $(D=37.32 \pm 0.5 \mathrm{~mm})$ followed by Virocid $(D=22.5 \pm 0.56 \mathrm{~mm})$, Quatovet $(D=21.88 \pm 0.51 \mathrm{~mm})$, and Savlon $(D=21.13 \pm 0.76 \mathrm{~mm})$, while Quatovet $(D=40.13 \pm 1.18 \mathrm{~mm})$ was found the most effective for $M$. aloeverae followed by Virocid $(D=38.63 \pm 74 \mathrm{~mm})$, Savlon $(D=35.5 \pm 0.69 \mathrm{~mm})$, and Virkon $S(D=22.1 \pm 0.3 \mathrm{~mm})$. So, considering the average of the inhibition zones against both $S$. lentus and Micrococcus spp., the efficacy of the commercial disinfectants can be concluded as Virocid > Quatovet $>$ Savlon > Virkon S > Lysol (Table 1). Individually, for S. lentus, the efficacy of the disinfectants was observed in descending order as Savlon $>$ Virocid > Quatovet > Virkon S > Lysol, for M. lentus, Virkon $\mathrm{S}>$ Virocid > Quatovet > Savlon > Lysol, and for M. aloeverae, Quatovet > Virocid > Savlon > Lysol > Virkon $S$ (Figure 4). Moreover, Virocid showed the lowest MIC value, $10 \%(\mathrm{v} / \mathrm{v})$ for each of the bacterial species tested 


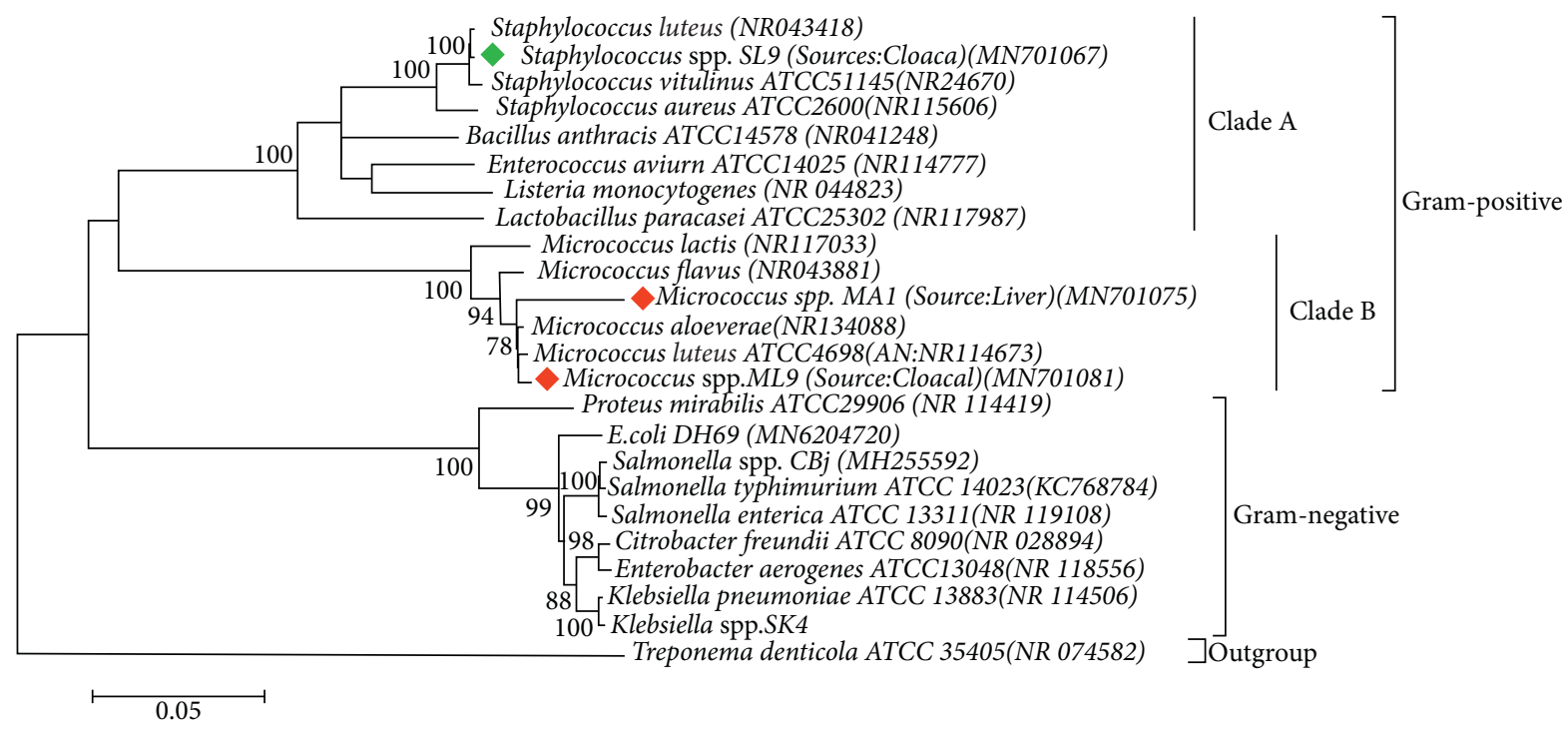

FIGURE 1: Phylogenetic tree predicted by the neighbor-joining method using $16 \mathrm{~S}$ rRNA gene sequences. The evolutionary distances were computed using the Kimura 2-parameter model method and are in the units of the number of base substitutions per site. The bootstrap considered 1000 replicates. The scale bar represents the expected number of substitutions averaged over all the analyzed sites. The optimal tree with the sum of branch length $=0.98517644$ is shown here. The results obtained with sequencing exhibited two different clusters, and we referred to them as clusters A and B. However, due to the high-sequence similarity, the nodes are not very stable and sequencing errors in some of the older sequences may well affect the topology of the tree. Cluster A contains Staphylococcus lentus. Cluster B contains both Micrococcus luteus and Micrococcus aloeverae strains. Treponema denticola was used as outgroup.

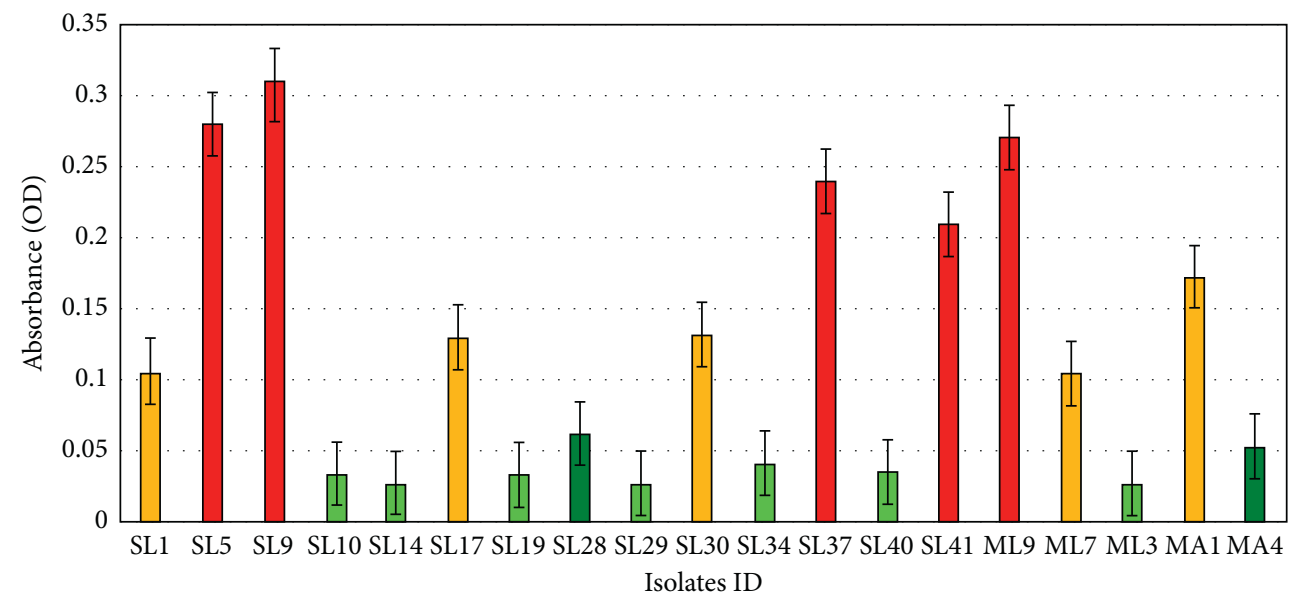

FIGURE 2: Results of biofilm formation in the microtiter plate assay by individual isolates. Red, yellow, light green, and bottle green indicated the strong, the moderate, the weak, and the lack of biofilm formation ability, respectively. Y-axis represents the numerical values of the absorbance of each isolate, and X-axis represents the isolates. Here, the absorbance values represent the average OD of each isolate. The S. lentus strains: SL1, SL5, SL9, SL10, SL14, SL17, SL19, SL28, SL29, SL30, SL34, SL37, SL40, and SL41; the M. luteus strains: ML9, ML7, and ML3; and M. aloeverae strains: MA1,and MA4 showed OD of $0.106,0.28,0.31,0.034,0.0273,0.13,0.033,0.062,0.027,0.132,0.041,0.24,0.035,0.21,0.273,0.104,0.028,0.173$, and 0.053 , respectively.

TABLE 1: Size of the zones of inhibition (mean \pm SD) of the organisms produced against each of the disinfectants tested (all data are presented in mm units).

\begin{tabular}{|c|c|c|c|c|c|c|}
\hline Organisms & Savlon & Virocid & Lysol & Virkon S & Quatovet & Alcohol \\
\hline RAPD group 1: Staphylococ & $37.13 \pm 0.7$ & $35.25 \pm 0.42$ & $30.13 \pm 0.88$ & $32.42 \pm 0.4$ & $33.9 \pm 0.67$ & $11.13 \pm 0.57$ \\
\hline RAPD group 2: Micrococcus luteus & $21.13 \pm 0.76$ & $22.5 \pm 0.56$ & $15.75 \pm 0.74$ & $37.32 \pm 0.5$ & $21.88 \pm 0.51$ & $10.5 \pm 0.69$ \\
\hline RAPD group 3: Micrococcus aloeverae & $35.5 \pm 0.69$ & $38.63 \pm 0.74$ & $31.38 \pm 0.82$ & $22.1 \pm 0.3$ & $40.13 \pm 1.18$ & $11.00 \pm 0.61$ \\
\hline
\end{tabular}




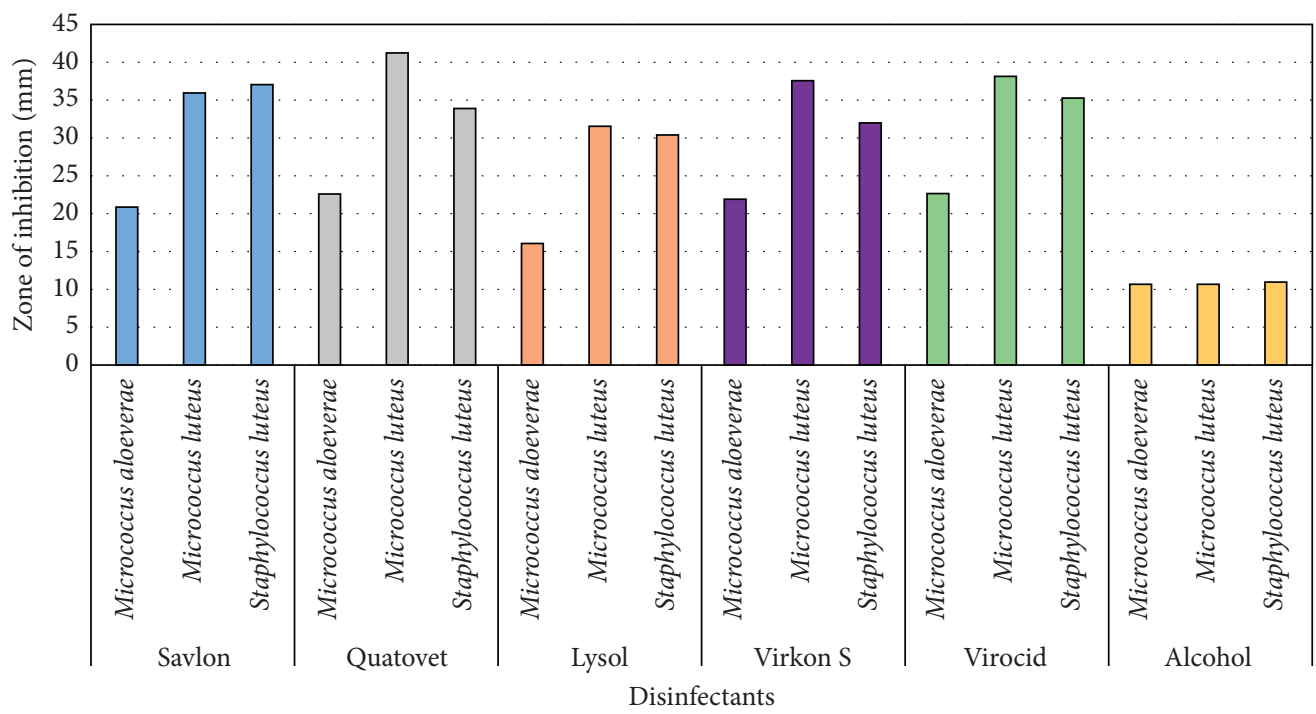

FIGURE 3: Diagrammatic representation of in vitro efficacy of disinfectants (100\% conc.) against Gram-positive bacteria. $Y$ axis represents the diameter of inhibition zone (mm). Here, blue, gray, pink, violet, green, and yellow indicate Savlon, Quatovet, Lysol, Virkon, S. Virocid, and alcohol, respectively.

(Table 2). Along with Virocid, Quatovet showed MIC value at $10 \%$ in case of both $S$. lentus and M. luteus.

\subsection{Correlation between the Efficacy and the Concentration of} Disinfectants. Agar well diffusion assay using the varying concentrations of each disinfectant showed that the efficacy of each disinfectant decreased with decreasing concentration (Table 3). But the inhibition zone diameter was of $\geq 62.5 \%$ of the inhibition zone diameter observed at absolute concentration at $\geq 50 \%$ concentration of each commercial disinfectant. However, alcohol failed to produce any inhibition zone at $60 \%$ concentration in case of $M$. aloeverae, at $50 \%$ concentration in case of $S$. lentus, and at $40 \%$ concentration in case of $M$. luteus, while none of the tested isolates showed resistance to any commercial disinfectant up to $30 \%$ concentration of the disinfectants (Figure 5).

\section{Discussion}

An effective sanitation plan for biosecurity of the poultry is based on the appropriate selection of disinfectants, which should consider the contaminants present and their sensitivity to the available disinfectants [31]. While among diverse microorganisms of poultry origin, the streptococci-micrococci group of bacteria is one of the predominant contaminants of poultry representing about $35 \%$ to $92 \%$ of the total poultry contaminants $[8,15,31]$, no data for these organisms have been reported from the poultry sector of Bangladesh, let alone the efficacy of the commonly used disinfectants against the organisms. Therefore, the current study targeted this group of poultry microbes and found that S. lentus was more prevalent $(32 / 102,31.37 \%)$ than micrococci including $M$. luteus $(7 / 102,6.86 \%)$ and $M$. aloeverae $(4 / 102,3.9 \%)$. Such a difference in the prevalence of staphylococci and micrococci was previously reported in another study [32]. Moreover, S. lentus is frequently reported to be isolated from poultry sources along with other coagulase-negative staphylococci $[20,33,34]$. However, they are not considered prominent poultry pathogens, although they are associated with various lesions in commercial poultry flocks [35]. But the most threatening concern of staphylococci from animal sources is to transfer antibiotic resistance genes to human pathogens [20] as well as dissemination of the disinfectant resistance genes [11]. The antibiogram results of $S$. lentus isolates showed that the highest resistance was observed against chloramphenicol followed by erythromycin and doxycycline, respectively (Supplementary Table 1). Although the use of erythromycin in poultry feeds was banned in the past due to the reports of significantly higher resistance among staphylococci of animal origin compared to those of human origin $[34,36]$, the antibiogram result indicated the possible breach of that regulation by relevant personnel. On the contrary, $100 \%$ sensitivity to imipenem, cefepime, and gentamycin was observed (Table S1). However, S. lentus of animal origin may also pose the risk of zoonosis considering the report of peritonitis in a peritoneal dialysis patient caused by the organism of animal origin [33].

On the other hand, $M$. luteus and $M$. aloeverae which were found in the study were initially thought of as nonpathogens, but they are now regarded as conditional pathogens [37]. While M. aloeverae is mostly nonpathogenic with rare reports of virulence [38] and usually not reported from poultry samples, $M$. luteus was found to be associated with pneumonia [38], endocarditis [37], septic arthritis [38], etc. in humans. Notably, opportunistic M. luteus was responsible for causing morbid diseases in fish [39]. So, the common practice of using poultry feces as fish feeds/fertilizer without any prior treatment may also contribute to the dissemination of diseases in fish [8]. Besides, this practice along with using eggshells as the calcium supplement in 


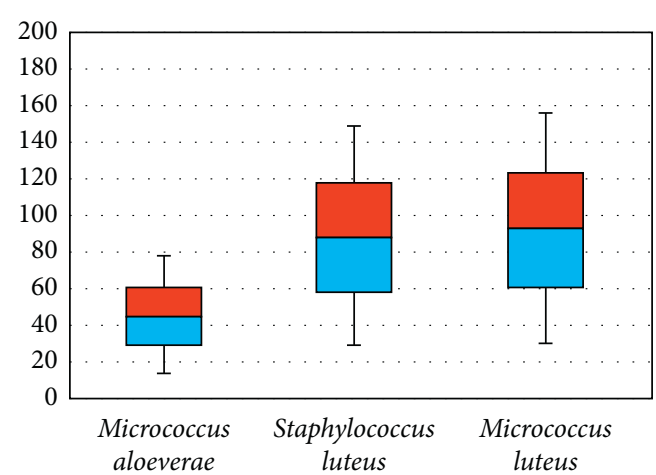

(a)

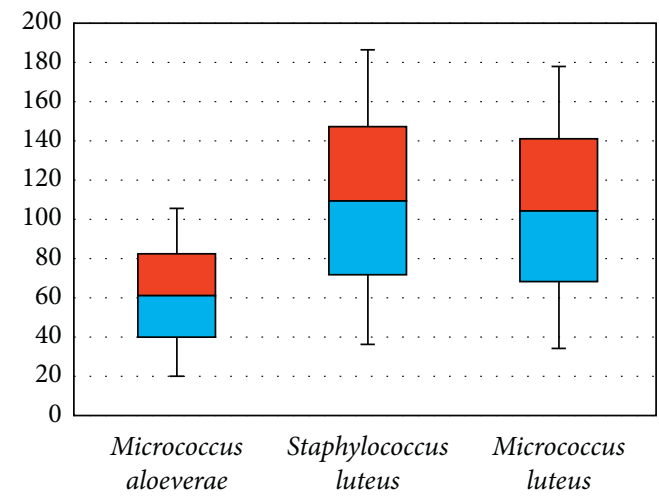

(c)

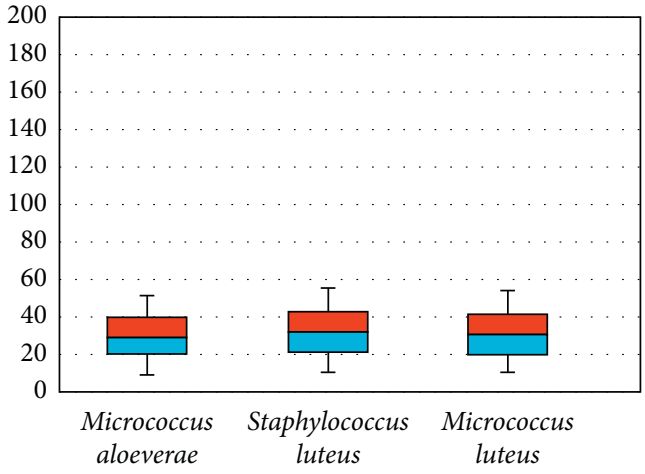

(e)

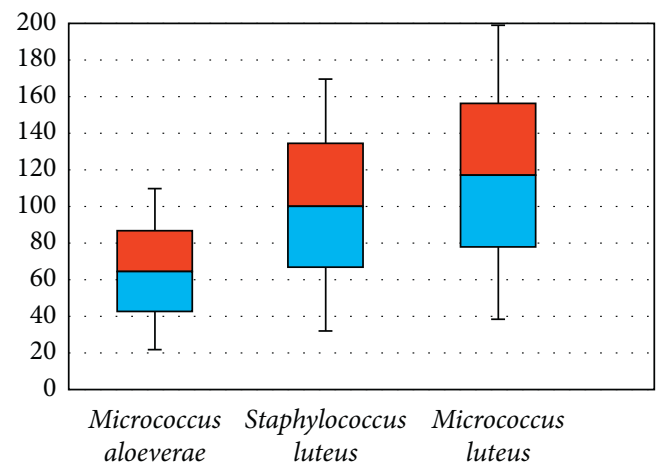

(b)

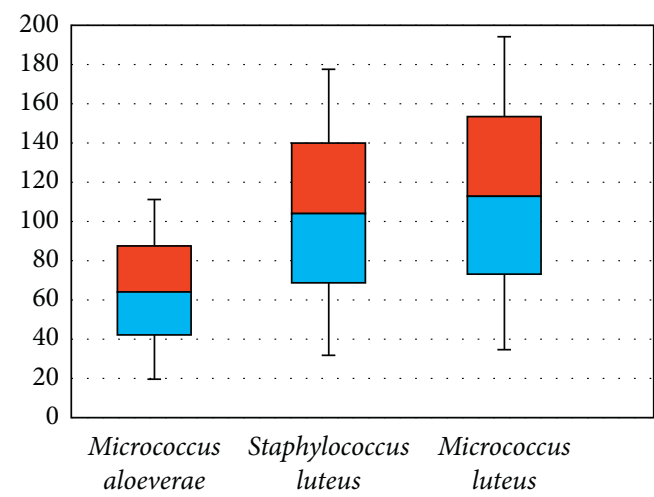

(d)

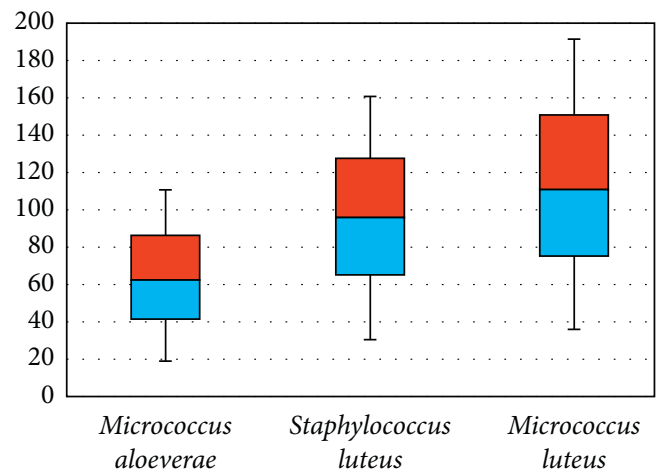

(f)

FIGURE 4: Box and Whisker plot (min/max, lower/upper quartiles and median) showing overall disinfection efficacy of various disinfectants against streptococci/micrococci groups of bacteria. $Y$ axis shows the average diameter of inhibition zones. Here, (a) Lysol; (b) Quatovet; (c) Savlon; (d) Virocid; (e) Alcohol; (f) Virkon S.

TABle 2: Minimum inhibitory concentration (MIC) values of the disinfectants as determined for S. lentus and Micrococcus spp. by broth dilution.

\begin{tabular}{|c|c|c|c|c|c|}
\hline $\begin{array}{l}\text { Disinfectants } \\
\text { Bacterial group }\end{array}$ & Savlon (\%) & Virocid (\%) & Lysol (\%) & Virkon S (\%) & Quatovet (\%) \\
\hline Staphylococcus lentus & 20 & 10 & 30 & 10 & 10 \\
\hline Micrococcus luteus & 30 & 10 & 40 & 20 & 10 \\
\hline Micrococcus aloeverae & 40 & 10 & 50 & 60 & 20 \\
\hline
\end{tabular}

poultry diet [17] may be partially responsible for the high prevalence of antibiotic resistance in human/animal and environmental isolates. However, all micrococci isolates in this study were sensitive to azithromycin and trimethoprim in addition to imipenem, cefepime, and gentamycin like staphylococci isolates, although resistance to doxycycline was observed (Figure S2 and Table S1). Apart from antibiotics, all of the streptococci and micrococci isolates were 
TABLE 3: Average diameter of the inhibition zones at different concentrations of the disinfectants tested against Staphylococcus lentus and Micrococcus spp.

\begin{tabular}{|c|c|c|c|c|c|c|c|c|c|}
\hline Disinfectants & Organisms & Dose $100 \%$ & Dose $90 \%$ & Dose $80 \%$ & Dose $70 \%$ & Dose $60 \%$ & Dose $50 \%$ & Dose $40 \%$ & Dose $30 \%$ \\
\hline \multirow{3}{*}{ Savlon } & Micrococcus aloeverae & 21.1 & 22 & 20 & 19 & 18.5 & 16 & 15 & 14 \\
\hline & Micrococcus luteus & 36 & 35 & 33 & 32 & 32 & 28 & 26 & 26 \\
\hline & Staphylococcus lentus & 37 & 36 & 33 & 32.5 & 31 & 30 & 27 & 22 \\
\hline \multirow{3}{*}{ Quatovet } & Micrococcus aloeverae & 22.5 & 21 & 20 & 20 & 19 & 19 & 15 & 15 \\
\hline & Micrococcus luteus & 41.1 & 37 & 37.5 & 37 & 36 & 34 & 32 & 30 \\
\hline & Staphylococcus lentus & 33.9 & 31 & 30 & 30 & 26 & 26 & 25.5 & 24 \\
\hline \multirow{3}{*}{ Lysol } & Micrococcus aloeverae & 16 & 16 & 16.5 & 16 & 12 & 10 & 10 & 8 \\
\hline & Micrococcus luteus & 31.7 & 29 & 29 & 27.5 & 25 & 24 & 23 & 20 \\
\hline & Staphylococcus lentus & 30.5 & 28 & 26 & 26.5 & 26 & 23.5 & 21 & 21 \\
\hline \multirow{3}{*}{ Virocid } & Micrococcus aloeverae & 22.8 & 21 & 21 & 21 & 19 & 18.5 & 16.5 & 15 \\
\hline & Micrococcus luteus & 38.1 & 38 & 38 & 35.5 & 34 & 34 & 31 & 29.5 \\
\hline & Staphylococcus lentus & 35.2 & 36 & 33 & 32.5 & 32 & 29 & 29 & 26 \\
\hline \multirow{3}{*}{ Alcohol } & Micrococcus aloeverae & 10.5 & 9 & 9 & 10 & 0 & 0 & 0 & 0 \\
\hline & Micrococcus luteus & 10.8 & 10.5 & 10.5 & 10.5 & 10 & 8 & 0 & 0 \\
\hline & Staphylococcus lentus & 11 & 12 & 12.5 & 12 & 12 & 0 & 0 & 0 \\
\hline
\end{tabular}

All the data are presented as unit, $\mathrm{mm}$.

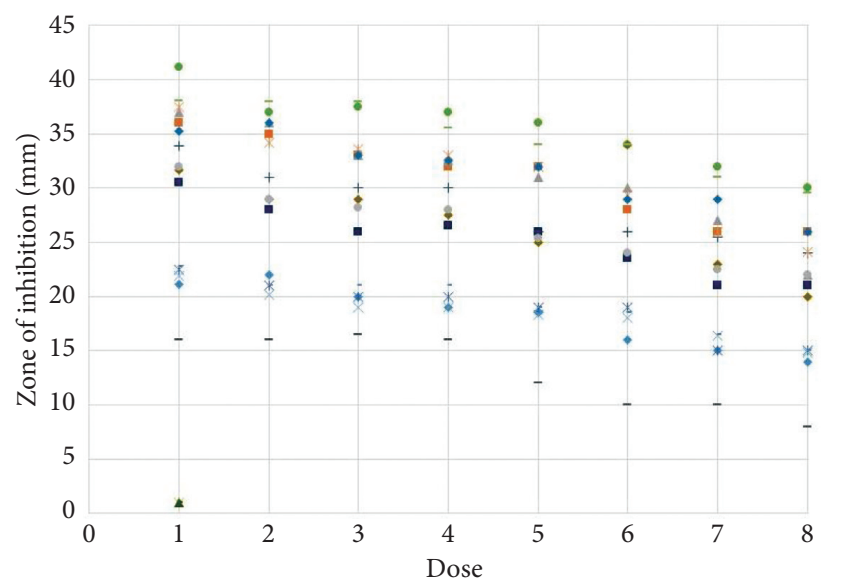

- Savlon micrococcus aloeverae

- Savlon micrococcus luteus

Savlon staphylococcus luteus

* Quator et micrococcus aloeverae

- Quator et micrococcus luteus

+ Quator et staphylococcus luteus

Lysol micrococcus aloeverae

- Lysol micrococcus luteus

FIGURE 5: Inhibition zone diameters of selected isolates of micrococci/staphylococci organisms against the disinfectants tested at different concentrations varying from $100 \%$ to $30 \%$ dose concentrations. $X$ axis represents the concentrations and $Y$ axis represents the diameters of inhibition zones in millimeter $(\mathrm{mm})$.

challenged against frequently used commercial disinfectants (Savlon, Virocid, Lysol, Quatovet, and Virkon S) along with alcohol, as different commercially available disinfectants are alcohol based. Each of these disinfectants was of different active compounds, although Virocid (5th generation) and Quatovet (3rd generation) have quaternary ammonium compound (QAC) in common with the rest of the components differing from each other. Efficacy tests revealed that no single disinfectant was equally effective against all three species tested in both broth dilution and agar well diffusion tests, although commercial ones were more effective than alcohol. While alcohol gave the smallest zones of inhibition against the test isolates, the total absence of inhibition zone in presence of alcohol was previously reported [40]. Besides, similar to our findings, the efficacy of alcohol based disinfectants tested by the same method was also reported below the satisfaction level previously [31]. Hence, the reason could probably be a limitation of the testing method itself, as alcohol, being volatile, might have evaporated before it got into contact with the test organisms. However, followed by alcohol, benzalkonium chloride based Lysol was found least effective, although this class of disinfectant has been reported to be effective previously [40]. Even Lysol was reported to be more effective than Savlon against micrococci [40], which was quite opposite to our findings according to both methods applied.

On the other hand, comparing the size of inhibition zones against three species tested, QAC based Quatovet was found to be one of the best choices for disinfectants in Bangladesh, while resistance to Quatovet was observed in Egypt due to its prolonged use in poultry [41]. The efficacy of the other QACs containing disinfectant, Virocid, slightly differed from Quatovet in both methods. That was probably due to the differences in synergy of QACs with other constituents of those disinfectants. Virkon S was found quite effective especially in the case of $S$. lentus and M. luteus. However, despite the limitations of agar well diffusion method including dependence of test efficiency on characteristics, properties, and composition of agar media, solubility of disinfectants and diffusion ability of disinfectant solutions on agar media, lacking the ability to correlate 
disinfectants' efficacy with exposure time, etc. [31], the results were found in excellent or good agreement with the findings of MIC determined by the broth dilution method. Besides, to validate the findings, the common poultry pathogens such as Salmonella, Klebsiella, and E. coli retrieved from laboratory depository were also challenged against the disinfectants. While Gram-negative organisms tend to be more resistant to disinfectant compared to Grampositive organisms [40,42], disinfectants showed slightly different efficacy pattern from that obtained with Grampositive organisms (Figure S3-S5). Quatovet was found most potent against all three Gram-negative isolates followed by Virkon S, Savlon, and Virocid (Table S2). But similar to the efficacy testing with Gram-positive isolates, alcohol followed by Lysol was found least effective.

However, diluting disinfectants with water is a common practice in most of the poultry farms of Bangladesh to make the sanitation programs economically more feasible. But the efficacy of the disinfectants depends on the correct dilution [31]. Efficacy usually decreases with decreasing concentration of disinfectants, although a satisfactory level of efficacy was noticed up to $30 \%$ of disinfectant concentration. Besides, at 30\% disinfectant concentration, Virocid retained even $\geq 81 \%$ inhibition zone diameters of those obtained at absolute concentration $(x)$ indicating the lowest effect of dilution on the efficacy followed by Quatovet $(x \geq 78 \%)$ and Savlon $(x \geq 76 \%)$, respectively (Table 3 ). Lysol showed the highest deviation of efficacy with dilution $(x \geq 62.5 \%)$. Virkon S, Virocid, and Quatovet showed the least fluctuation in the efficacy with decreasing concentration in case of $M$. aloeverae. But unfortunately, storage before application, exposure to UV, or extreme temperature reduce the efficacy of the diluted disinfectants notably [9], while these field effects were not simulated during the study. So, the same level of efficacy of the diluted disinfectants cannot be claimed at the field level. On the other hand, the gradual decrease in the efficacy of Virkon $S$ with decreasing concentration should be considered carefully, as the higher dose of Virkon $S$ has been reported to interfere with the hatchability and survivability of chicks [42]. Besides, biofilm interferes with the efficacy of the disinfectants making the organisms 1000 times more resistant to disinfectants [9]. On top of that, biofilmforming property is the major virulence factor and prime cause of multidrug resistance in S. lentus [35], while isolates of S. lentus in this study included both strong and moderate biofilm producers. On the other hand, only 1 isolate of $M$. luteus was strong biofilm producer and all $M$. aloeverae were weak biofilm producers, although in vitro monoculture of micrococci might show lesser biofilm-forming ability compared to their ability at natural environment because of the association with other species [9]. However, the disinfectants showed that the organism dependent pattern of efficacy. M. luteus was least sensitive to all of the disinfectants followed by $S$. lentus and M. aloeverae, respectively, although none of the isolates were resistant to any of the disinfectants tested.
However, the study is not denying its limitations, as the in situ performance of the disinfectants might show slight difference from these in vitro findings depending on the environmental and other factors. Nevertheless, each of the test results was validated by ensuring reproducibility.

\section{Conclusions}

Quaternary ammonium compounds based disinfectants, Quatovet, Virocid, Virkon S, and chlorhexidine gluconatecetrimide based Savlon, were found more potent than benzalkonium chloride based Lysol and Alcohol against staphylococci and micrococci, the predominate contaminants of poultry. Due to frequent fluctuations in the efficacy and emergence of the resistance against disinfectants, sanitation programs should be based on the current evaluation of disinfectants' efficiency against the microflora present in the facilities. So, the poultry industry, being a promising economical sector of Bangladesh, should be taken into consideration for the more vigorous analysis of the microflora and their sensitivity to the disinfectants rendering disinfection program to be more effective and economically feasible.

\section{Data Availability}

All data used to support the findings of this study are included within the article.

\section{Conflicts of Interest}

The authors declare that the research was conducted in the absence of any commercial or financial relationships that could be construed as a potential conflict of interest.

\section{Authors' Contributions}

O.S. carried out the studies (sampling, sequencing, and molecular and data analysis). O.S. and A.I. carried out the statistical and data analysis. O.S. and N.N.R. participated in drafting the manuscript. I.S. carried out the revised studies (MIC and new disinfectant testing). M.A.H., M.S., and M.M.R developed the hypothesis, supervised the whole work, and helped to prepare and revise the manuscript. All authors read and approved the final manuscript.

\section{Acknowledgments}

The authors would like to acknowledge Samina Momtaz, Assistant Professor, Department of Microbiology, University of Dhaka, for her support. The authors would like to acknowledge Bangabandhu Science and Technology Fellowship Trust for supporting Otun Saha with Ph.D. fellowship and University Grants Commission, Bangladesh, for the grant awarded to Nadira Naznin Rakhi. This research was funded by Bangladesh Academy of Science-United States Department of Agriculture (BAS-USDA), grant number BAS-USDA PALS DU LSc-34. 


\section{Supplementary Materials}

Figure S1: gel electrophoretograms image of RAPD typing. Figure S2: diagrammatic representation of antibiotic resistance pattern of the isolates. Figure S3: diagrammatic representation of in vitro efficacy of the disinfectant $(100 \%$ conc.). Figure S4: Box and Whisker plot ( $\mathrm{min} / \mathrm{max}$, lower/ upper quartiles, and median) showing overall disinfection efficacy of various disinfectants against the Gram-negative bacteria. Figure S5: percentage of the resistance of isolated Gram-negative microorganisms against specific disinfectant at $100 \%$ to $30 \%$ dose conc. Table S1: antimicrobial susceptibility of the isolates as suggested by CLSI guideline. Table S2: zone of inhibition size (mean \pm SD) descriptive statistics of the tested Gram-negative organisms for the disinfectant comparison. (Supplementary Materials)

\section{References}

[1] M. M. Khan, B. Chowdhury, M. R. Bhuiyan, M. J. Uddin, M. Dawlatana, and M. Rahim, "Nutrient content of poultry feed used in different poultry farms of Bangladesh," Bangladesh Journal of Scientific and Industrial Research, vol. 43, no. 1, pp. 1-2, 2008.

[2] M. A. Hamid, M. A. Rahman, S. Ahmed, and K. M. Hossain, "Status of poultry industry in Bangladesh and the role of private sector for its development," Asian Journal of Poultry Science, vol. 11, no. 1, pp. 1-3, 2017.

[3] J. T. Hemen, J. T. Johnson, E. E. Ambo, V. S. Ekam, M. O. Odey, and W. A. Fila, "Multi-antibiotic resistance of some gram negative bacterial isolates from poultry litters of selected farms in Benue state," International Journal of Scientific \& Technology, vol. 2, no. 8, pp. 543-547, 2012.

[4] O. Saha, M. N. Hoque, O. K. Islam, M. M. Rahaman, M. Sultana, and M. A. Hossain, "Multidrug-resistant avian pathogenic Escherichia coli strains and association of their virulence genes in Bangladesh," Microorganisms, vol. 8, no. 8, p. $1135,2020$.

[5] A. Conan, F. L. Goutard, S. Sorn, and S. Vong, "Biosecurity measures for backyard poultry in developing countries: a systematic review," BMC Veterinary Research, vol. 8, no. 1, p. 240, 2012.

[6] H. Çakmur, L. Akoğlu, E. Kahraman, and M. Atasever, "Evaluation of farmers' knowledge-attitude-practice about zoonotic diseases in Kars, Turkey," Kafkas Journal of Medical Sciences, vol. 5, no. 3, pp. 87-93, 2015.

[7] H. Barua, P. K. Biswas, K. E. Olsen, S. K. Shil, and J. P. Christensen, "Molecular characterization of motile serovars of Salmonella enterica from breeder and commercial broiler poultry farms in Bangladesh," PloS One, vol. 8, no. 3, Article ID e57811, 2013

[8] N. A. Rimi, R. Sultana, M. Muhsina et al., "Biosecurity conditions in small commercial chicken farms, Bangladesh 2011-2012," EcoHealth, vol. 14, no. 2, pp. 244-258, 2017.

[9] K. Stringfellow, P. Anderson, D. Caldwell et al., "Evaluation of disinfectants commonly used by the commercial poultry industry under simulated field conditions," Poultry Science, vol. 88, no. 6, pp. 1151-1155, 2009.

[10] K. N. Islam, K. N. Monira, R. Sultana, and I. M. Azharul, “The effect of timsen and ambicide as disinfectant on hatchability traits of kasila broiler parents eggs in Bangladesh," Livestock Research for Rural Development, vol. 19, p. 44, 2007.
[11] G. McDonnell and A. D. Russell, "Antiseptics and disinfectants: activity, action, and resistance," Clinical Microbiology Reviews, vol. 14, no. 1, p. 227, 2011.

[12] J. Gong, R. J. Forster, H. Yu et al., "Diversity and phylogenetic analysis of bacteria in the mucosa of chicken ceca and comparison with bacteria in the cecal lumen," FEMS Microbiology Letters, vol. 208, no. 1, pp. 1-7, 2002.

[13] J. Schulz, L. Formosa, J. Seedorf, and J. Hartung, "Measurement of culturable airborne staphylococci downwind from a naturally ventilated broiler house," Aerobiologia, vol. 27, no. 4, pp. 311-318, 2011.

[14] L. Ellerbroek, "Airborne microflora in poultry slaughtering establishments," Food Microbiology, vol. 14, no. 6, pp. 527-531, 1997.

[15] W. Yang, M. Guo, G Liu et al., "Detection and analysis of fine particulate matter and microbial aerosol in chicken houses in Shandong Province, China," Poultry Science, vol. 97, no. 3, pp. 995-1005, 2017.

[16] M. I. Cook, S. R. Beissinger, G. A. Toranzos, R. A. Rodriguez, and W. J. Arendt, "Trans-shell infection by pathogenic microorganisms reduces the shelf life of non-incubated bird's eggs: a constraint on the onset of incubation?" Proceedings of the Royal Society of London. Series B: Biological Sciences, vol. 270, no. 1530, pp. 2233-2240, 2003.

[17] M. A. Islam, "Poultry products processing and marketing system in Bangladesh," Pakistan Journal of Biological Sciences, vol. 6, no. 10, pp. 883-886, 2003.

[18] D. K. Ali, H. M. Ismail, and A. E. Abdelgadir, "Status of milk and meat hygiene in Sudan," J. of Vet. Med. and Animal Prod.vol. 11, no. 1, p. 3, 2013.

[19] M. Awan and M. Matsumoto, "Heterogeneity of Staphylococci and other bacteria isolated from six-week-old broiler chickens," Poultry Science, vol. 77, no. 7, pp. 944-949, 1998.

[20] A. Wieliczko, J. Król, T. Piasecki, M. Mazurkiewicz, and Z. Staroniewicz, "Occurrence and characteristics of staphylococci isolated from poultry," Medycyna Weterynaryjna, vol. 58, no. 5, pp. 348-352, 2002.

[21] R. M. Smibert, J. E. Faber, and H. M. DeVolt, "Studies on "airsac" infection in poultry: 2. bacterial flora of the respiratory system of turkeys associated with avian PPLO (pleuropneumonia-like organisms) in artificially induced aerosaccitis," Poultry Science, vol. 38, no. 6, pp. 1398-1404, 2012.

[22] A. Sultana, O. Saha, A. Rahman Sid, A. Saha, S. Hussain, and T. Islam, "Molecular detection of multidrug resistance pathogenic bacteria from protective materials used by healthcare workers (HCW); Bangladesh scenario," Journal of Applied Sciences, vol. 18, no. 1, pp. 48-55, 2018.

[23] J. G. Holt, N. R. Krieg, PH. A. Sneath, J. T. Staley, and S. T. Williams, Bergey's Manual of Determinative Bacteriology, p. 787, Williams and Wilkins, Baltimore, MD, USA, 1994.

[24] S. Momtaz and M. A. Hossain, "Occurrence of pathogenic and multidrug resistant Salmonella spp," Bioresearch Communications, vol. 4, no. 2, pp. 506-515, 2018.

[25] S. Kumar, G. Stecher, and K. Tamura, "MEGA7: molecular evolutionary genetics analysis version 7.0 for bigger datasets," Molecular Biology and Evolution, vol. 33, no. 7, pp. 1870-1874, 2016.

[26] S. Stepanović, D. Vuković, I. Dakić, B. Savić, and M. ŠvabićVlahović, "A modified microtiter-plate test for quantification of staphylococcal biofilm formation," Journal of Microbiological Methods, vol. 40, no. 2, pp. 175-179, 2000.

[27] M. N. Hoque, A. Istiaq, R. A. Clement et al., "Insights into the resistome of bovine clinical mastitis microbiome, a key factor 
in disease complication," Frontiers in Microbiology, vol. 11, no. 860 , pp. $1-18,2020$.

[28] C. Valgas, S. M. d. Souza, E. F. A. Smânia, and A. Smânia, "Screening methods to determine antibacterial activity of natural products," Brazilian Journal of Microbiology, vol. 38, no. 2, pp. 369-380, 2007.

[29] G. I. Olasehinde, J. A. Akinyanju, and A. A. Ajayi, "Comparative antimicrobial activity of commercial disinfectants with naphtolics," Research Journal of Microbiology, vol. 3, no. 4, pp. 262-268, 2008.

[30] G. Wu, Q. Yang, M. Long et al., "Evaluation of agar dilution and broth microdilution methods to determine the disinfectant susceptibility," The Journal of Antibiotics, vol. 68, no. 11, pp. 661-665, 2015.

[31] L. Jiang, M. Li, J. Tang et al., "Effect of different disinfectants on bacterial aerosol diversity in poultry houses," Frontiers in Microbiology, vol. 9, p. 2113, 2018.

[32] E. Paba, A. Chiominto, A. M. Marcelloni, A. R. Proietto, and R. Sisto, "Exposure to airborne culturable microorganisms and endotoxin in two Italian poultry slaughterhouses," Journal of Occupational and Environmental Hygiene, vol. 11, no. 7, pp. 469-478, 2014.

[33] M. Rivera, M. D. Dominguez, N. R. Mendiola, G. R. Roso, and C. Quereda, "Staphylococcus lentus peritonitis: a case report," Peritoneal Dialysis International: Journal of the International Society for Peritoneal Dialysis, vol. 34, no. 4, pp. 469-470, 2014.

[34] A. Marek, D. Stepień-Pyśniak, E. Pyzik, J. Wilczyński, and S. Winiarczyk, "Occurrence and characterization of Staphylococcus bacteria isolated from poultry in western poland," Berliner und Munchener tierarztliche Wochenschrift, vol. 129, no. 3-4, pp. 147-152, 2016.

[35] I. H. Al-Azawi, A. H. Al-Hamadani, and S. O. Hasson, "Association between biofilm formation and susceptibility to antibiotics in staphylococcus lentus isolated from urinary catheterized patients," Nano Biomedicine and Engineering, vol. 10, no. 2, pp. 97-103, 2018.

[36] R. Peces, E. Gago, F. Tejada, A. S. Laures, and J. AlvarezGrande, "Relapsing bacteraemia due to Micrococcus luteus in a haemodialysis patient with a perm-cath catheter," Nephrology Dialysis Transplantation, vol. 12, no. 11, pp. 2428-2429, 1997.

[37] S. H. Song, H. S. Choi, S. K. Ma, S. W. Kim, J.-H. Shin, and E. H. Bae, "Micrococcus aloeverae-a rare cause of peritoneal dialysis-related peritonitis confirmed by $16 \mathrm{~S}$ rRNA gene sequencing," Journal of Nippon Medical School, vol. 86, no. 1, pp. 55-57, 2019.

[38] A. Pękala, E. Paździor, J. Antychowicz et al., "Kocuria rhizophila and Micrococcus luteus as emerging opportunist pathogens in brown trout (Salmo trutta linnaeus, 1758) and rainbow trout (oncorhynchus mykiss walbaum, 1792)," Aquaculture, vol. 486, pp. 285-289, 2018.

[39] P. Singh, A. Rani, and S. Pal, "Comparative efficacy of disinfectant against routine lab bacterial contaminants," WJPR (World Journal of Pharmaceutical Research), vol. 3, no. 9, pp. 709-715, 2014.

[40] Z. M. Gehan, W. Anwer, H. M. Amer, I. M. El-Sabagh, A. Rezk, and E. M. Badawy, "In vitro efficacy comparisons of disinfectants used in the commercial poultry farms," International Journal of Poultry Science, vol. 8, no. 3, pp. 237-241, 2009.

[41] C. B. Gutiérrez-Martín, S. Yubero, S. Martínez, R. Frandoloso, and E. F. Rodríguez-Ferri, "Evaluation of efficacy of several disinfectants against Campylobacter jejuni strains by a suspension test," Research in Veterinary Science, vol. 91, no. 3, pp. e44-e47, 2011.
[42] M. Gholami-Ahangaran, S. Shahzamani, and M. Yazdkhasti, "Comparison of virkon S (r) and formaldehyde on hatchability and survival rate of chicks in disinfection of fertile eggs," Revue. Médecine Vétérinaire.vol. 167, no. 1-2, pp. 4549, 2016. 